\title{
Welcome to the Arctic Circle
}

\author{
Jonathan K. Han, MD
}

"You're a f-ing Korean!"

This was the greeting I received from a previously comatose 25-year-old Eskimo woman, rudely awakened into a place of Narcan-induced hyperawareness and harsh ER examination room lights, as she suspiciously surveyed my face; mine was the same face she had seen just 3 days before, as I repaired a laceration on her arm. On that visit, however, there was no such recognition, only a sigh of learned resignation.

The paramedics who accompanied her, two Inuit men who knew her well, who were familiar with her sad history of alcoholism, drug abuse and domestic violence, squirmed with embarrassment and barely concealed laughter. "Welcome to the Arctic Circle," I thought to myself.

For a moment, I suspended my own disbelief as this somewhat comical, but unfortunately all too familiar, situation played out before me. I am a second-generation Korean American and was raised as one of the few Asian Americans in a mostly white, middle class, rural Ohio town. My father was the first Korean Protestant minister in Ohio, and he and my mother had quietly and bravely emigrated from Korea to Ohio some 45 years ago.

I grew up experiencing much racism and prejudice. Facing provocative racist taunts by children and adults alike and being ridiculed for my Asian features were painful reminders of my "perpetual foreigner" status. As a child, I was constantly encouraged by my parents to respond to racism by "ignoring other people's ignorance." This was reinforced by the silence of society at large-the topic of racism against Asians had not yet entered the public consciousness or debate. Like many children, I struggled with desires to conform, to be

Submitted, revised, 11 June 2003.

From the New Kensington Family Health Center, New Kensington, Pennsylvania. Address correspondence to Jonathan K. Han, MD, New Kensington Family Health Center, 301 Eleventh Street, Suite C, New Kensington, PA 15068 (e-mail: hanjk@upmc.edu). accepted by my non-Korean peers. Participating in athletics, including basketball, was one way I tried to "fit in." However, even as a collegiate varsity basketball player, I could not escape racist jeers by spectators at many of our games. Chants like "put the Chinaman in the game" were intimidating to me, and the sad irony that even athletic achievement could not spare me from ridicule was blatantly obvious.

Feeling somewhat lost, somewhere in between cultures of Korea and America, I searched for a place to fit in, to be anonymous, to not stand out simply because of my physical appearance. These struggles of identity intensified as I grew older, even as I moved toward a career in medicine.

One of the reasons I had chosen medicine in general, and family medicine in particular, was to be of service to others, to walk in my father's footsteps, as it were. I was drawn to working with the medically underserved, with those who had faced extra battles and who had suffered after missed or unavailable opportunities. Having worked in several Indian Health Service facilities, I had enjoyed the fact that my physical appearance resembled those of the Native Americans I served. After all, we were distant relatives, sharing ancestors who had crossed the Bering Straits land bridge. I enjoyed it when patients would ask, "What tribe are you from? Did you know my uncle?"

And yet here in the rural Arctic was a cruel reminder that it is human nature to first recognize the differences between each other before we affirm our similarities. I had forgotten how, within this tiny northern Alaskan village of 1000 people, composed mostly of Eskimos, a small community of about 50 Koreans lived and thrived. These relative newcomers owned and operated four out of the five businesses in this Inuit town. Not far beneath the human tundra, however, there existed deep resentments between the Alaskan natives, who struggled with poverty and subsistence, and the Koreans, who were viewed as holding the purse 
strings. These conflicts were similar to those among Korean business owners and their predominantly African American neighbors and patrons in economically depressed areas of Los Angeles and Manhattan. Once again, the bitter determinants of "us" versus "them," though decided along racial lines, were rooted in both real and perceived disparities in wealth, power, and opportunity. Here in the frozen north, among the Inuit, with whom I had naively felt a bond solely because of physical appearance and distant ancestry, I could not avoid the painful stereotyping and assumptions that arise when we separate ourselves from others by race and class.

As these thoughts flew in a flurry, or not, I suddenly turned to my hyperawake patient, who was now smiling with boldness and acuity, and replied, "In all my years of living in America, I've been called a chink, a jap, and a slant-eyed gook. This is the first time anyone ever correctly called me a Korean!”

She smiled even more broadly, and the Inuit paramedics now felt comfortable laughing out loud.

I added, "Now, you'll have to hold still while I insert this rubber tube into your nose to pump your stomach out."

Although I was the one now smiling broadly, the initial satisfaction I felt in the irony of the situation unfolding in this way was short-lived, giving way quickly to concerns about the seriousness of her medical condition.

If only my conflicting emotions of anger, vindication, and guilt were so short-lived. 